\title{
UMA ANÁLISE CRÍTICA DA TEORIA DA IGNORÂNCIA DELIBERADA A LUZ DO PRINCÍPIO DA IMPUTAÇÃO SUBJETIVA
}

\section{Gisele Mendes de Carvalho ${ }^{1}$ Gerson Faustino Rosa ${ }^{2}$}

\begin{abstract}
Resumo
O presente trabalho tem como meta a análise crítica e a exploração de um grande problema jurídico-penal da atualidade, qual seja, a importação da teoria da ignorância deliberada para viabilizar a inculpação de condutas que não se enquadrem nos critérios de imputação previstos em nosso ordenamento jurídico, violando o princípio da imputação subjetiva. Para tanto, analisou-se a origem histórica da teoria da ignorância deliberada, apresentando julgados dos Direitos inglês, norte-americano, espanhol e brasileiro. Demonstrou-se, ademais disso, a sua utilização inicial no sistema anglo-saxão e, posteriormente, a sua importação para o sistema continental. Adiante, discorreu-se acerca das proposta de definição e delimitação doutrinária e jurisprudencial da presente teoria, seguidas de uma análise crítica frente a sua incompatibilidade com o princípio político-criminal de garantia da imputação subjetiva.
\end{abstract}

Palavras-chave: Ignorância Deliberada; Cegueira Deliberada; Culpabilidade; Imputação Subjetiva.

\section{INTRODUÇÃO}

Ante a impossibilidade de "retorno" ou reconstrução de um modelo do assim chamado Direito Penal Liberal, ou "moderno", cujos traços fundamentais foram construídos pelo movimento da ilustração em fins do século XVIII e princípio do século XIX, rompendo com os postulados do Ancièn Régime, e frente à constatação de uma progressiva expansão do Direito Penal da pós-modernidade, característico de uma sociedade de risco, há quem advogue pela volta de um Direito centrado na proteção dos bens essencialmente personalistas e do patrimônio, com estrita vinculação aos princípios de garantia, paralelamente a um Direito de consequências

\footnotetext{
${ }^{1}$ Pós-Doutora em Direito Penal pela Universidade de Zaragoza, Espanha. Professora Associada de Direito Penal na Universidade Estadual de Maringá (UEM). E-mail: giselemendesdecarvalho@yahoo.es

${ }^{2}$ Professor de Direito Penal e Ciência Política nos cursos de pós-graduação e de graduação da Universidade Estadual de MaringáPR (UEM). Professor de Direito Penal e coordenador da Pós-graduação em Ciências Penais na UNOESTE de Presidente Prudente-SP. Professor credenciado junto à Escola Superior de Educação em Direitos Humanos do Estado do Paraná (ESEDH). Professor de Direito Penal nos cursos de pós-graduação da Escola Superior da Advocacia (ESA), da UNIFAMMA, das Faculdades Maringá e da Faculdade Integrado de Campo Mourão-PR. Pesquisador do CNPq, com experiência na área do Direito, com ênfase em Direito Penal e Política Criminal. Doutorando em Direito pela Faculdade de Direito de São Paulo-SP (FADISP). E-mail: gersonfaustinorosa@gmail.com
} 
atenuadas e garantias flexibilizadas, face à necessidade de célere resposta estatal a delitos contra bens jurídicos difusos (meio ambiente, saúde pública, direitos do consumidor etc).

A intenção que rege tal proposta é, indubitavelmente, a de recuperar sua configuração como um Direito estrito de garantias do cidadão, diante da intervenção repressiva do Estado, onde a grandeza da resposta penal é compensada por um instrumental de regras garantidoras da liberdade do homem face ao poder punitivo do Estado, legitimado e limitado tanto pelo conteúdo do ius poenale, como do exercício do ius puniendi.

Garantir-se-ia com isso, uma dinâmica na atividade administrativa jurisdicional do Estado ao responder de forma pronta às violações de bens jurídicos difusos, onde a inexistência de sanções tradicionais, como a pena de prisão, cuja falência já se observa há tempos, permitiria uma flexibilização ou atrofia dos mecanismos garantistas de ordem material e processual, em prol de uma celeridade reclamada.

Esse Direito Penal, porém, cuja denominação "liberal" relaciona-se às características essenciais do movimento de superação do autoritarismo medieval e que pretendem alguns reconstruir agora, nunca existiu como tal. Impossível, portanto, sua volta.

Isso porque, mesmo que a hipótese da concretude daquele modelo seja aceita, tal reconstrução ignora a presença de determinadas características históricas observadas no ambiente europeu que desencadeou o Iluminismo, estruturado ante uma rígida proteção do Estado, assim como de certos princípios de organização social incompatíveis com a realidade da sociedade "pós-moderna", onde o incremento das relações de risco fomentam um funcionalismo penal que ultrapassa as necessidades constantes naquele período da história. Qualquer tentativa, nesse sentido, se apresentaria como anacrônica, inadequada portanto, em face da missão atual do Direito Penal.

E assim, evoca-se a intervenção estatatal punitivista inerente a essa sociedade de risco - fortemente presente nos atuais dias sombrios - promotora do perigo e do terror, a ampliar o alcance e o conteúdo dos textos jurídico-penais, impulsionados pela falsa ideia de promoção da paz e da ordem sociais.

Nesta senda, a sensação de vulnerabilidade vivenciada pelos indivíduos, mesmo sendo mais comunicacional do que factual - pois sentida integralmente pelo cidadão em seu dia a dia -, incrementa a criminalização de outras condutas penalmente indiferentes até o momento, bem como, a elaboração de "soluções" de cunho profilático, que se rapidamente utilzadas, "justificam" toda e qualquer ingerência penal do Estado.

Daí que determinados assuntos estão sempre em território de férteis discussões, pois de tempos em tempos, voltam à baila, pleiteando novas respostas de natureza revanchista e com maior severidade, em decorrência da profusa necessidade de contenção da delinquência.

$\mathrm{Na}$ incansável busca por uma boa razão para punir, as noveis tendências intentam diversas leituras de 
múltiplas ordens. Tome-se, à título de exemplo, a importação da teoria da ignorância deliberada, da common law, como uma "terceira forma" de vinculação da responsabilidade penal subjetiva, com intuito de "solucionar" determinados casos em que o agente ignora voluntariamente, em sua conduta, dados penalmente relevantes.

Diante disso, analisar-se-á a teoria da ignorância deliberada, desde seu surgimento no Direito anglosaxão, explanando acerca das definições doutrinárias até aqui apresentadas e das vantagens e desvantagens que trazem em seu bojo, propondo, ainda, uma reflexão objetiva sobre o direito a uma responsabilização subjetiva, oriunda de um Estado democrático de Direito, frente ao esvaziamento do conteúdo humano da conduta.

Empregar-se-á, para tanto, os métodos lógico-dedutivo e indutivo-argumentativo, através de análises fundamentais e qualitativas, tendo como recursos bibliografia nacional e estrangeira, periódicos e recentes decisões dos tribunais.

\section{EVOLUÇÃO HISTÓRICA DA TEORIA DA IGNORÂNCIA DELIBERADA}

\section{Willful blindness: a teoria da cegueira deliberada na inglaterra}

Os primeiros contornos da, hodiernamente intitulada pela doutrina espanhola, teoria da ignorância deliberada, foram dados após o julgamento, ainda em 1861 na Inglaterra, do caso Regina vs. Sleep, onde discutiuse a absolvição deste por malversação de bens do Estado. Sleep era um ferrageiro, acusado de embarcar containers em um navio, com parafusos de cobre com a marca (sinal em forma de flecha) indicativa da propriedade do Estado inglês. Na ocasião, Sleep foi considerado culpado pelo júri por desvio de bens públicos, delito que requer, como elemento do tipo, o conhecimento de tal circunstância (bem público) pelo agente. Entretanto, ante a arguição da defesa de que o ferrageiro ignorava a propriedade estatal dos bens, o magistrado o absolveu por entender que o réu desconhecia a origem daqueles ${ }^{3}$.

A fundamentação do julgador acerca da revogação do decreto condenatório do júri baseou-se nos fatos de que o júri não considerou que Sleep sabia da marcação dos bens, nem tampouco, se abstivera intencionalmente de sabê-lo, pois estavam dentro de containers. Surge então, um novo entendimento judicial no sentido de que, caso restasse provado que o acusado tinha a intenção de se abster, seria ele merecedor de uma resposta equivalente àquela dada em caso de efetivo conhecimento ${ }^{4}$.

Ainda na Inglaterra, outro caso de destaque a ser mencionado foi o Bosley vs. Davies, em 1875, quando o

\footnotetext{
${ }^{3}$ ROBBINS, Ira P. The Ostrich Instruction: Deliberate Ignorance as a Criminal Mens Rea. The Journal of Criminal Law Criminology. Chicago, 1990, p. 195. Disponível em: scholarlycommons.law.northwestern.edu/jclc/vol81/iss2/1/. Acesso em 02 set. 2016. Tradução livre.
} 
tribunal condenou Davies, proprietário de uma pensão, por permitir a prática de jogos ilegais em suas instalações, mesmo diante do réu alegar não ter ciência da ocorrência da prática ilegal em seu estabelecimento, afirmando o decreto condenatório que o conhecimento real não é obrigatório, pois as circunstâncias evidenciam que o réu e seus funcionários foram coniventes com a prática ilícita 5 .

Desenvolve-se a partir de então, a Teoria Willful Blindness, que serviu de precedente para diversos provimentos judiciais condenatórios, sem o esclarecimento, no entanto, se perfazia-se necessária a demonstração da suspeita ou da possibilidade de ciência, por parte do acusado, acerca do ilícito. Ou ainda, se esta equiparação somente seria utilizada para os casos em que as alegações de desconhecimento pela defesa se mostrassem absolutamente inverossímeis. Ocorreu que, no fim do século XIX, a "doutrina" da cegueira deliberada foi estabelecida como uma alternativa ao elemento cognitivo no ordenamento jurídico-penal inglês ${ }^{6}$.

\section{Ostrich instructions: a teoria das instruções do avestruz nos estados unidos}

No mesmo sentido, nos Estados Unidos, em 1899, a Suprema Corte aplicou o que denominou de Ostrich Instructions, ao revisar a condenação de Spurr, presidente do Commercial National Bank of Nashville, no caso Spurr vs. United States, acusado por ter certificado diversos cheques sem provisão de fundos, emitidos por um cliente. Sendo assim, diante da previsão legal exigindo, para a condenação, uma conduta intencionalmente dirigida à violação dos preceitos que regulam a emissão de cheques, a Suprema Corte norte-americana entendeu que, se o acusado certificou cheque com a intenção de que o emitente da cártula obtivesse dinheiro do banco, em que pese não haver em sua conta provisão para tanto, tal certificação, além de ilícita, deve ser-lhe imputada em decorrência do propósito de violar a lei. E isso pode ser presumido quando o acusado se mantém, deliberadamente na ignorância acerca da existência ou inexistência de saldo suficiente na conta do correntista, ou ainda, quando se mostra indiferente a respeito de seu dever de verificar tal circunstância?

E a jurisprudência norte-americana passa a valer-se desse precedente e repete-o, em outros vários provimentos jurisdicionais, solidificando o entendimento de que a ignorância deliberada e o conhecimento equiparar-se-iam, independentemente da verificação da existência de um dever de conhecimento ou informação por parte do agente ${ }^{8}$.

A partir de 1962, as discussões acerca da cegueira deliberada no Direito Penal estadounidense, passaram

\footnotetext{
${ }^{4}$ KLEIN, Ana Luiza. A doutrina da cegueira deliberada aplicada ao delito de lavagem de capitais no Direito Penal brasileiro. Porto Alegre: Edipucrs, 2012, p. 2-3, Disponível em: <ebooks.pucrs.br/edipucrs/anais/cienciascriminais/III/4.pdf>. Acesso em 02 set. 2016. ${ }^{5}$ ROBBINS, Ira P. Op. cit., p. 197.

${ }^{6}$ RAGUÉS I VALLĖS, Ramon. La ignorancia deliberada en derecho penal. Barcelona: Atelier, 2007, p. 66-67.

${ }^{7}$ ROBBINS, Ira P. Op. cit., p. 196.
} 
a condicionar-se pelas disposições nacionais do Model Penal Code, proposto pelo American Law Institute, que tratou, na seção 2.02, dos "requisitos gerais da culpabilidade", sem fazer menção expressa à willful blindness, mas prevendo em seu item 7, que o conhecimento da alta probabilidade satisfaz a exigência de conhecimento9 considerando-se que, há conhecimento por parte do agente quando houver, no caso concreto, alta probabilidade da ocorrência do fato delitivo ${ }^{10}$.

$\mathrm{Na}$ segunda metade do século XX, a willful blindness passou a ser aplicada em diversas decisões proferidas por tribunais inferiores, especialmente em crimes falimentares, sendo que, nos idos de 1970, fora também amplamente utilizada nos casos de tráfico de drogas, dentre os quais se destaca o United States vS. Jewell ${ }^{1}$, firmando-se o entendimento de que, quem é consciente da alta probabilidade da existência de um crime e não faz o necessário para confirmar tal existência, será tratado similarmente àquele que detém a plena certeza sobre a ocorrência delitiva, pois a esta equivale. E para justificar sua decisão, o tribunal norte-americano invocou, dentre outras, a ideia de que a ignorância deliberada e o conhecimento positivo apresentam um mesmo grau de culpabilidade ${ }^{12}$.

Ademais disso, doutrina da cegueira deliberada ampliou seu raio de atuação, sendo também aplicada à criminalidade ambiental ${ }^{13}$ e a corporativa em geral, em delitos de informática, de lavagem de capitais ${ }^{14}$,

\footnotetext{
${ }^{8}$ RAGUÉS I VALLÈS, Ramon. Op. cit., p. 67-68.

${ }^{9}$ MODEL PENAL CODE - 2.02 General Requirements of Culpability. (7) Requirement of knowledge satisfied by knowledge of high probability. When knowledge of the existence of a particular fact is an element of an offense, such knowledge is established if a person is aware of a high probability of its existence, unless he actually believes that it does not exist. Disponível em: <www.cs.xu.edu/ osborn/main/lawSchool/CriminalHtml/bottomScreens/Briefs/Model Penal Code Section 2.02.htm>. Acesso em: 02 set. 2016. Tradução livre.

${ }^{10}$ Ramon Ragués i Vallès, sobre a interpretação de que a ignorância deliberada estaria prevista no Model Penal Code, assevera que, se assim for, o texto legislativo deixou de fora então, todos os demais casos em que o sujeito decide não continuar investigando por suspeitar que sua conduta poderia subsumir-se aos elementos objetivos de determinada infração penal, o que é mais grave. Traz ainda, o voto esposado pelo magistrado do caso United States vs. Jewell, Anthony M. Kennedy, para quem a lei exige o conhecimento e, assim, a ignorância, razoável ou não, não está apta a ensejar um decreto condenatório (RAGUÉS I VALLÈS, Ramon. Op. cit., p. 73). Tradução livre.

${ }^{11}$ Trata-se de caso que, em 1976, Jewell foi condenado por cruzar a fronteira entre o México e os Estados Unidos transportando maconha no porta-malas de seu veículo, e mesmo tendo alegado que não sabia o que trazia consigo, recebeu provimento jurisdicional desfavorável afirmando que "a ignorância deliberada e o convencimento positivo têm um mesmo grau de culpabilidade” (RAGUÉS I VALLÈS, Ramon. Op. cit., p. 73). Tradução livre.

${ }^{12}$ Vide Ramon Ragués i Vallès explicando a decisão da Corte norte-americana (RAGUÉS I VALLÈS, Ramon. Mejor no saber: sobre la doctrina de la ignorancia deliberada en Derecho penal. Discusiones: Ignorancia Deliberada y Derecho Penal. v. 13-2, 2013, p. 15. Disponível em: <http://www.academia.edu/22655140/Discusiones_XIII_Ignorancia_deliberada_y_derecho_penal>. Acesso em: 02 set. 2016).

${ }^{13} \mathrm{O}$ case referenciado a propósito da criminalidade ecológica é United States vs. MacDonald \& Watson Waste Oil Co., solucionado pelo Tribunal de Apelação em 1991 (933 F. 2d 35 [1st Cir. 1991]). Tradução livre.

${ }^{14}$ Trata-se de caso em que Ellen Campbell, corretora de imóveis, vendeu a Lawing, suposto traficante de drogas, um imóvel avaliado em aproximadamente U\$ 200.000,00 (duzentos mil dólares), dos quais, U\$ 60.000,00 (sessenta mil dólares) foram pagos "por fora" e em espécie, entregues em pequenos pacotes de compras. Campbell foi condenada por ter fechado os olhos deliberadamente a fim de concluir a venda e coletar sua comissão, não importando a fonte do numerário. ESTADOS UNIDOS
} 
destacando-se ainda, a sua utilização com a finalidade de fundamentar a responsabilidade das pessoas jurídicas nos casos em que algum dirigente tenha se colocado deliberadamente, em uma situação de desconhecimento ${ }^{15}$.

Em meados de 2011, a Ostrich Instructions Doctrine foi confirmada pela Corte Suprema estadounidense, em sentença sobre o caso Global-Tech Appliances, Inc. et al. vs. SEB S.A. ${ }^{16}$, a propósito de um procedimento civil por violação de direito de patente. No caso, o Tribunal afirmou que "a doutrina da ignorância deliberada está bem assentada no Direito Penal e entende que não existe nenhuma objeção em empregá-la também em questões cíveis nos casos em que as normas exigem para sua infração, determinado conhecimento" ${ }^{17}$.

\section{A teoria da ignorância deliberada no sistema continental}

No âmbito da Civil Law, foi a Segunda Sala da Suprema Corte espanhola pioneira em fazer menção à teoria da ignorância deliberada, em 10 de janeiro do ano 2000, em decisão de relatoria de Joaquín Giménez García que revisava condenação pelo delito de receptação e drogas, em razão de o acusado ter transportado considerável quantidade de dinheiro a um paraíso fiscal, afirmando em sua defesa não ter conhecimento da origem ilícita do numerário, proveniente do tráfico de drogas. $\mathrm{O}$ órgão julgador rebateu a alegação de ignorância argumentando que o acusado José tinha conhecimento de que o dinheiro procedia do comércio ilegal de drogas - coisa que nega -, pois era óbvio tendo em vista a considerável quantia e a natureza claramente clandestina da operação, pois quem se coloca em situação de ignorância deliberada, é dizer, não quer saber aquilo que se pode e deve conhecer, e ainda, se beneficia da situação (José cobrava 4 \% de comissão), está assumindo e aceitando todas as possibilidades oriundas do negócio em que participa, e portanto, deve responder por suas consequências ${ }^{18}$.

No mesmo sentido foram proferidas várias outras sentenças fazendo menção à ignorância deliberada ${ }^{19}$, entretanto, sem uniformidade em sua delimitação, de modo que, a cada novo pronunciamento da Suprema Corte

DA AMERICA. United States vs. Campbell. 05 jun. 1982. Disponível em: <http://ftp.resource.org/courts.gov/c/F2/977/977.F2d.854.91-5695.html>. Acesso em: 02 set. 2016. Tradução livre.

${ }^{15}$ BECK, Francis. A Doutrina da Cegueira Deliberada e sua (In) Aplicabilidade ao Crime de Lavagem de Dinheiro. Revista de Estudos Criminais. Sapucaia do Sul, n. 41, p. 45-68, set. 2011.p. 47-48.

16 Vide case 563 U.S.; 131 S. Ct. 2060; 179 L. Ed. 2d 1167 (2011). Disponível em: <https://www.supremecourt.gov/opinions/10pdf/10-6.pdf>. Acesso em: 02 set. 2016.

${ }^{17}$ Sem embargo, ao precisar o alcance da willful blindness, a Corte entende, no item 07 da Seção 2.02 do Model Penal Code, que esta teoria exige que o acusado atue com consciência de seus atos, o que restringe notadamente seu âmbito de aplicação e que, por mais que o Tribunal sustente expressamente o contrário, acaba por confundir a doutrina da ignorância deliberada com a recklessness (é a desconsideração, figura similar ao dolo eventual continental), que ocorre quando o agente despreza o conhecimento de um risco substancial e injustificado de que ocorra determinado elemento material da figura típica, ou de que este acabe resultando de sua conduta (RAGUÉS I VALLÈS, Ramon. Op. cit., p. 16; ROBBINS, Ira P. Op. cit., p. 195).

${ }^{18}$ Vide sentença n. ${ }^{\circ}$ 1637/1999, proferida pela Sala Segunda do Tribunal Supremo, nos autos do processo ROJ: STS 16/2000. Disponível em: <http://www.poderjudicial.es/search/>. Acesso em: 03 set. 2016. Tradução livre.

${ }^{19}$ Vide: ROJ: STS 7.363/2000, sentença n. ${ }^{0} 1.583$ de 16/10/2000; ROJ: ATS 9.878/2007, sentença n.o 1.329 de 12/07/2007; ROJ: ATS 11.858/2007, sentença n. ${ }^{\circ} 1.459$ de 20/09/2007, dentre outras. Disponível em: <http://www.poderjudicial.es/search/>. Acesso em: 03 set. 2016. 
espanhola, alteravam-se os requisitos exigidos para sua configuração. Ora denominada teoria, ora princípio, a ignorância deliberada já foi tratada como sendo indiciária do elemento volitivo do dolo, depois também o foi como indiciária do elemento cognitivo daquele, e até como substitutivo do elemento subjetivo do tipo. Nesta esteira, foram prolatadas outras diversas condenações por condutas dolosas e culposas, passando a se fazer referência ao "princípio" da ignorância deliberada como se fosse questão unânime no Direito espanhol, e que, por sua vez, não demandava maiores explicações ${ }^{20}$.

No Brasil, aponta-se como leading case da ignorância deliberada a sentença condenatória proferida no julgamento do maior furto da história do país, ocorrido no Banco Central do Brasil, em Fortaleza-CE, no dia 06 de agosto de 2005, de onde foram subtraídos mais de 160 milhões de reais em notas de R \$ 50,00 (cinquenta reais). Consta da decisão que, com a finalidade de "lavar" o dinheiro oriundo do crime, os sócios de uma revendedora de automóveis mercanciaram onze veículos que totalizavam a importância de $\mathrm{R} \$ 730.000,00$, sendo que os clientes ainda deram um adiantamento de mais R 230.000,00 para aquisições futuras, perfazendo o numerário de R \$ 980.000,00, pagos em dinheiro, mais precisamente em notas de $\mathrm{R} \$ 50,00$ acondicionadas em sacos. O juiz condenou os sócios da revendedora como incursos no delito de lavagem de capitais (art. 1. ${ }^{\circ}$, VII, da Lei n. ${ }^{\circ}$ 9.613/98) por entender que, embora não tivessem conhecimento da origem ilícita dos valores, tinham eles elementos suficientes para desconfiar da origem ilícita do dinheiro, e ainda assim, optaram por ignorar deliberadamente tal fato, sendo-lhes aplicada a Doutrina das Instruções do Avestruz ${ }^{21}$.

Em 17 de outubro de 2012, durante as discussões no Supremo Tribunal Federal da Ação Penal n.o 470, que envolve diversos acusados de participar de um enorme esquema de compra de votos parlamentares, conhecida como o caso do "Mensalão", o tema voltou à tona. Em sessão plenária, o Ministro Celso de Mello teria mencionado admitir "a possibilidade de configuração do crime de lavagem de valores, mediante o dolo eventual, exatamente com apoio no critério denominado por alguns como 'teoria da cegueira deliberada', que deve ser usado com muita cautela"22. O julgador explicou que, conforme essa teoria, o agente finge não perceber determinada situação de ilicitude para alcançar a vantagem pretendida ${ }^{23}$.

\footnotetext{
${ }^{20}$ RAGUÉS I VALLÈS, Ramon. Op. cit., p. 58.

${ }^{21}$ Vide: Ação penal n 200581000145860, da $11^{\text {a }}$ Vara da Seção Judiciária do Ceará. Disponível em <http://www.jfce.jus.br>. Acesso em 03 set. 2016.

${ }^{22}$ Vide: Ação penal 470. Disponível em: <ftp://ftp.stf.jus.br/ap470/InteiroTeor_AP470.pdf>. Acesso em 02 set. 2016.

${ }^{23}$ SILVEIRA, Renato de Mello Jorge. Cegueira deliberada e lavagem de dinheiro. Boletim IBCCrim. v. 246, 2013, p. 3. Disponível em: <http://www.ibccrim.org.br/boletim_artigo/4864-Cegueira-deliberada-e-lavagem-de-dinheiro>. Acesso em: 01 set. 2016.
} 


\section{AS PROPOSTAS DE DEFINIÇÃO DA TEORIA DA IGNORÂNCIA DELIBERADA}

Inicialmente denominada willful blindness (cegueira voluntária) ${ }^{24}$ pela jurisprudência inglesa, foi a posteriori, batizada de ostrich instructions doctrine (doutrina das instruções do avestruz) pela doutrina norteamericana, e ainda, conscious avoidance doctrine (doutrina da evitação da consciência) ${ }^{25}$, ficou consagrada como ignorância deliberadano ano 2000, após o julgamento do Tribunal Supremo espanhol ${ }^{26}$.

E com base na doutrina da cegueira deliberada, passou a entender a jurisprudência estadounidense que atua dolosamente o agente quando realiza os elementos objetivos do tipo ignorando algumas peculiaridades do caso concreto por ter se colocado, voluntariamente, numa posição de alienação diante de situações suspeitas, procurando não se aprofundar no conhecimento das circunstâncias objetivas. No mesmo sentido, a Suprema Corte da Espanha considerou como dolosa a conduta daquele que, mesmo diante de situação suspeita, perfaz o núcleo típico, colocando-se em condição de ignorância, sem se importar em conhecer mais a fundo as circunstâncias de fato ${ }^{27}$. Há quem advogue ainda, na doutrina nacional, ser dolosa a conduta perpetrada em situação de "autocolocação em estado de desconhecimento", quando o agente não procura inteirar-se detalhadamente das circunstâncias de fato de uma situação suspeita ${ }^{28}$.

São inúmeras as tentativas de definir precisamente, bem como, de delimitar o alcance da doutrina da ignorância deliberada. Em 1994, Husak e Callender, traçaram os seus primeiros contornos e indicaram a necessidade de se constatar, pelo menos, três elementos na conduta para se poder afirmar que o agente atuou ignorando deliberadamente dados penalmente relevantes: (1) o agente deve ter uma suspeita justificada acerca da presença de elementos típicos em sua conduta. Assim, consideram-se somente aquelas situações em que existirem boas razões objetivas para desconfiar, afastando-se os casos em que a suspeita é infundada ( $\mathrm{vg}$. pessoas que sofrem paranoias ou outros delírios); (2) a informação desprezada pelo agente deve estar disponível, de modo que ele possa acessá-la por meios "viáveis, rápidos e ordinários"; (3) trata-se de um elemento motivacional, exigindo-se que o sujeito tenha um motivo para se manter alienado, fruto do o desejo consciente de exonerar-se de eventual

\footnotetext{
${ }^{24}$ ROBBINS, Ira P. Op. cit., p. 197. Tradução livre.

25 LUBAN, David. "Contrived Ignorance". Georgetown Law Review. v. 87. Toronto, 1999, p. 968. Disponível em: <http://scholarship.law.georgetown.edu/cgi/viewcontent.cgi?article=2765\&context=facpub $>$. Acesso em: 03 set. 2016. Tradução livre.

${ }^{26}$ Vide sentença n. ${ }^{\circ}$ 1637/1999, proferida pela Sala Segunda do Tribunal Supremo, nos autos do processo ROJ: STS 16/2000. Disponível em: <http://www.poderjudicial.es/search/>. Acesso em: 03 set. 2016. Tradução livre.

${ }^{27}$ LAUFER, Christian; GALVÃO DA SILVA, Robson A. A teoria da cegueira deliberada e o Direito Penal brasileiro. Boletim IBCCrim. v. 204, 2009, p. 2. Disponível em: <http://www.ibccrim.org.br/boletim_artigo/3980-A-teoria-da-cegueira-deliberada-eo-direito-penal-brasileiro $>$. Acesso em: 01 set. 2016.

${ }^{28}$ MORO, Sérgio Fernando. Sobre o elemento subjetivo no crime de lavagem. In: Lavagem de dinheiro: comentários a lei pelos juízes das varas especializadas em homenagem ao Ministro Gilson Dipp. BALTAZAR JUNIOR. José; MORO, Sérgio Fernando (org.). Porto Alegre: Livraria do Advogado, 2007, p. 100.
} 
culpa ou responsabilidade futura, caso seja descoberto. Restam afastados, assim, os casos em que o desconhecimento é fruto de mera estupidez ou falta de curiosidade ${ }^{29}$.

Em 1999, o também norte-americano David Luban, afirmou ser a cegueira deliberada uma "estratégia moral" do indivíduo que, a fim de negar a si mesmo o dilema (moral) que enfrenta ao delinquir, ignora deliberadamente dados relevantes da própria conduta, pois assim, esta lhe parecerá menos grave. Por isso a analogia ao avestruz, débil moral que esconde sua cabeça em um buraco para não enxergar aquilo que é evidente. Segundo Luban, o agente pode até ser equiparado a uma raposa quando optar decididamente por levar adiante uma conduta ilícita, buscando entretanto, a própria ignorância somente com intuito de se proteger frente à futura responsabilização criminal, o que the parece mais grave em virtude do elemento de cálculo adicionado. Note-se que, para Luban, a "motivação" do sujeito é o requisito de maior relevância, sendo que, haverá situações em que deverá o agente-ignorante deliberado (raposa) ser mais severamente reprovado, tal como aquele que conhece; e haverá ainda hipóteses em que a reprimenda deverá ser menor (avestruz) ${ }^{3031}$.

No início do século XXI, o espanhol Ramon Ragués i Vallès estabeleceu novos contornos a fim de estabelecer o raio de alcance da ignorância deliberada, e critica, em parte, as propostas de Husak e Callender e de Luban, especialmente em razão da dificuldade de se demonstrar se a ignorância é fruto de um desejo consciente de não saber, e não de estupidez. Assim, defende que o desconhecimento deve ser voluntário, ou quando menos, consciente, senão será somente ignorância (não deliberada). Ademais disso, a decisão de não conhecer não pode ser confundida com os motivos que levaram o agente a buscar a ignorância. Nessa senda, com intuito de sanar os problemas apontados, Ragués i Vallès estabelece que, para se falar em punição nos casos de ignorância deliberada,

\footnotetext{
${ }^{29}$ Os norte-americanos Douglas Husak e Craig Callender defendem que a equiparação da ignorância deliberada com o conhecimento é totalmente contrária ao princípio da legalidade, sendo tal doutrina utilizada unicamente por necessidades políticocriminais. HUSAK, Douglas N.; CALLENDER, Craig A. "Willful Ignorance, Knowledge, and the 'Equal Culpability' Thesis: A Study of the Deeper Significance of the Principle of Legality”, Winconsin Law Review, Madison, 1994, p. 34. Disponível em: <https://litigation-essentials.lexisnexis.com/>. Acesso em 04 set. 2016. Tradução livre.

${ }^{30}$ Para Luban, uma análise completa dos comportamentos (raposas e avestruzes) requer que se desdobre a cegueira deliberada em dois momentos. O primeiro, quando o agente realiza manobras para evitar conhecer aquelas circunstancias que não deseja (screening actions); o segundo refere-se às condutas nas quais o agente não seria penalmente responsável em caso de ter sido verdadeiramente ignorante (unwitting misdeed). Sendo assim, nos casos em que o autor se comporta como uma avestruz, a ignorância não equivaleria ao dolo. Mas nos casos em que o autor se comporta como uma raposa, seria ele o principal beneficiário da ignorância. Logo, não seria justo, então, recompensá-lo. Senão ele se beneficiaria duas vezes: primeiro pela maior facilidade com que atingiria seu objetivo, e segundo, para escapar do castigo por meio da ignorâcia deliberada (LUBAN, David. Op. cit., p. 969). Tradução livre.

${ }^{31}$ Sem embargo, a distinção entre o dolo e a culpa não tem nada a ver com a estrutura mais ou menos altruísta que motivou o autor. Pode-se dizer que há o dolo-altruísta e a culpa-egoísta. Imagine-se, por exemplo, alguém que, a pedido de uma vítima, que não suportando mais viver com as agonias de um câncer capaz de prolongar seu sofrimento por anos, administra uma injeção letal, não restará excluída de sua conduta a intenção de matar (dolo-altruísta). Da mesma forma que o ato de um médico desatento, por odiar o paciente, não terá o poder, por si só, de justificar a culpa (culpa-egoísta) (GRECO. Luís. Comentario al artículo de Ramón Ragués. Discusiones: Ignorancia Deliberada y Derecho Penal. v. 13-2, 2013, p. 15. Disponível em: <http://www.academia.edu/22655140/Discusiones_XIII_Ignorancia_deliberada_y_derecho_penal>. Acesso em: 02 set. 2016). Tradução livre.
} 
a conduta do agente deverá conter os seguintes requisitos ${ }^{32}$ :

1. ${ }^{\circ}$ ) Ausência de representação suficiente dos elementos do tipo penal, traduzindo-se no fato de que o agente não conte com os conhecimentos que permitem afirmar que agiu com o grau de representação exigido pelo elemento subjetivo do tipo respectivo no mesmo instante em que realiza a ação ou omissão objetivamente típica. É pois, menos que o dolo. Desta forma, se estaria abrangendo tanto os casos em que o indivíduo não tem a menor suspeita acerca da concorrência do elementos típicos, quanto aqueles em que o sujeito desconfia, contudo sua suposição é tão leve e imprecisa que não se pode afirmar que agiu dolosamente ${ }^{33}$.

2.o) Capacidade de obter a informação ignorada, uma vez que só se pode dizer que decidiu ignorar deliberadamente o indivíduo que possuía condições de conhecer. E tal capacidade (de conhecer) deve estenderse por toda a realização da conduta (ação ou omissão) típica. Essa determinação de desconhecer o que pode ser conhecido só reforça, segundo Ragués ${ }^{34}$, a indiferença do agente em relação aos bens jurídicos objetos da tutela penal. Assim, verificar-se-ia se o indivíduo estaria apto a conhecer os elementos do tipo, por meio da análise de dados referentes ao próprio sujeito, tais como, sua condição pessoal e sua escolaridade, viabilizando-se a aferição de sua capacidade (ou incapacidade) de obter o conhecimento necessário acerca da realização da conduta típica ${ }^{35}$.

3. ${ }^{\circ}$ Dever de obter a informação ignorada, o que é inerente a qualquer modelo de imputação subjetiva em que vigora o princípio da culpabilidade. Só é possível se responsabilizar alguém pela falta de conhecimento se

\footnotetext{
${ }^{32}$ RAGUÉS I VALLÈS, Ramon. Op. cit., p. 149-152. Tradução livre.

${ }^{33}$ RAGUÉS I VALLĖS, Ramon. Op. cit., p. 152. Para Feijoo Sánchez, essa falta de representação, se absoluta, nunca poderá fundamentar a imputação subjetiva a título de dolo. Dito de outra forma, se a mera "suspeita" não pode moldar a representação dos elementos objetivos do tipo, menos ainda, indicar a concordância intelectual do agente. No entanto, a conduta do agente-ignorante deve ser reveladora de uma grave indiferença em relação aos bens jurídicos penalmente tutelados, pois mesmo diante disso, o autor não desiste do plano concebido (FEIJOO SÁNCHEZ, Bernardo. La teoría de la ignorancia deliberada en Derecho penal: una peligrosa doctrina jurisprudencial. InDret: Revista para el análisis del Derecho. v. 3. Barcelona, 2015, p. 3. Disponível em: <http://www.indret.com/pdf/1153.pdf>. Acesso em: 05 set. 2016). Tradução livre.

${ }^{34}$ RAGUÉS I VALLÈS, Ramon. Op. cit., p. 152-153.

${ }^{35}$ Não se deve retomar aqui a confusão oriunda da doutrina da ação causal, onde misturavam-se os elementos subjetivos do tipo com os elementos da culpabilidade. A partir da doutrina da ação finalista, define-se que o dolo e a culpa integram a tipicidade, e a potencial consciência da ilicitude, a culpabilidade. E nesse passo, o conhecimento potencial dos elementos do tipo objetivo, não configuram o dolo eventual, diferentemente do que ocorre com o conhecimento potencial da ilicitude do fato, que pode sim dar ensejo à culpabilidade (Vide: WELZEL, Hans. O novo sistema jurídico-penal: uma introdução à doutrina da ação finalista. Trad. Luiz Regis Prado. 3. ed. São Paulo: Revista dos Tribunais, 2011, p. 41 e ss). Logo, o mínimo de representação das circunstâncias do tipo objetivo deverá estar efetivamente presente no momento da conduta, não se aceitando que o agente pudesse vir a ter um conhecimento mínimo exigido caso se esforçasse para tanto, pois "o conhecimento exigível para a configuração de qualquer espécie dolosa deve ser sempre atual, e não potencial” (LAUFER, Christian; GALVÃO DA SILVA, Robson A. Op. cit., p. 2). Mais ainda, "apenas o conhecimento da totalidade das circunstâncias da ação proporciona o conhecimento da ilicitude e permite aferir a presença do dolo" (GRACIA MARTÍN, Luis. Proyecto docente y de investigación en Derecho penal. p. 324, apud PRADO, Luiz Regis. Tratado de Direito Penal brasileiro: parte geral: volume 2. São Paulo: Revista dos Tribunais, 2014, p. 496). (grifei)
} 
houver o dever de conhecer o conteúdo ignorado ${ }^{36}$. Não se trata de um dever específico, mas é suficiente a simples inobservância do dever geral de atentar-se aos riscos associados à realização de comportamentos potencialmente lesivos a interesses alheios ${ }^{37}$.

4. ${ }^{\circ}$ Decisão de não conhecer por parte do agente, ou seja, que o estado de falta de representação decorra de uma decisão do próprio indivíduo. A opção pela ignorância deve ser voluntária, ou ao menos, consciente, podendo traduzir-se tanto em ações concretas que objetivem evitar a informação, com também em omissões do dever de conhecer ${ }^{38}$.

Dessa forma, encontra-se em estado de ignorância deliberada aquele que, diante da ausência de representação suficiente dos elementos do tipo penal, da capacidade e do dever de obter a informação ignorada decide não conhecê-la. Dito de outro modo, é o agente que podendo e devendo conhecer determinadas circunstâncias penalmente relevantes de sua conduta, toma deliberada ou conscientemente a decisão de manterse em estado de ignorância em relação a elas ${ }^{39}$.

Tais critérios são estabelecidos para viabilizar a punição daqueles que atuam, segundo Ramon Ragués, em "estado de ignorância deliberada em sentido estrito", pois, diante do entendimento majoritário da doutrina e dos sistemas penais continentais ${ }^{40}$, a falta de conhecimento da concorrência, em um determinado comportamento, dos elementos de uma figura delitiva impede considerar a conduta como dolosa, o que leva a impunidade ou, quando a lei permitir, a castigar tal comportamento como culposo ${ }^{41}$.

Assim, falar-se-ia em "ignorância deliberada em sentido estrito" quando o indivíduo, de forma

\footnotetext{
${ }^{36}$ Eis aqui, outro problema. Ao exigir do agente o "dever geral de obter a informação ignorada", Ragués toma como base um critério puramente empírico para aferição do dever de cuidado. Não há como sancionar um dever desprovido de correspondência normativa. Mais ainda, é inadmissível, em um Estado democrático de Direito, vez que a imputação de qualquer "fazer" deverá pautar-se pelo princípio da legalidade. Nesse sentido, é precisa a lição de Juarez Tavares ao dizer que "essa especificação do dever é necessária para impedir não só a criação de um dever geral de atuação, como para obstar que o direito penal se transforme em instrumento ideológico, meramente sancionador e repressivo. De conformidade com a Constituição, só deve o homem fazer aquilo que lhe é prescrito especificamente na lei (art. 5. ․, II)". E continua, "não existe um cuidado em si mesmo, senão associado a uma conduta normativamente determinada (...) a característica da conduta cuidadosa deve ser inferida das condições concretas, existentes no momento do fato, e da necessidade objetiva, naquele instante, de estabelecer os pressupostos do perigo de lesão ao bem jurídico, ou seja, a medida do cuidado não pode ser feita, exclusivamente, por um procedimento empírico, mas sim sob o complexo empírico-normativo" (TAVARES, Juarez. Direito Penal da Negligência: uma contribuição à Teoria do Crime Culposo. 2. ed. Rio de Janeiro: Lumen Juris, 2003, p. 240 e ss). No mesmo sentido, Welzel ressalva que "o conteúdo do cuidado objetivo no caso concreto é determinado, portanto, por meio de um critério 'intelectual' e um critério 'normativo”" (WELZEL, Hans. Op. cit., p. 98).

${ }^{37}$ RAGUÉS I VALLÈS, Ramon. Op. cit., p. 156-157. Tradução livre.

${ }^{38}$ RAGUÉS I VALLÈS, Ramon. Op. cit., p. 158. Tradução livre.

${ }^{39}$ Idem. Ibidem.

${ }^{40}$ Vide: WELZEL, Hans. Op. cit., p. 91; CEREZO MIR, José. Temas fundamentales de Derecho Penal. Santa Fe: RubinzalCulzoni, 2002, v. I, p. 34; PRADO, Luiz Regis. Op. cit., p. 382; MIR PUIG, Santiago. Direito penal: fundamentos e teoria do delito. Trad. Cláudia Viana Garcia e José Carlos Nobre Porciúncula Neto. São Paulo: Revista dos Tribunais, 2007, p. 210; BITENCOURT, Cezar Roberto. Teoria geral do delito: uma visão panorâmica da dogmática penal brasileira. Coimbra: Almedina, 2007, p. 166; BRANDÃO. Cláudio. Curso de Direito Penal: parte geral. 2. ed. Rio de Janeiro: Forense, 2010, p. 173.
} 
intencional, logra êxito em evitar a obtenção daqueles conhecimentos mínimos e essenciais para apreciar uma atuação a título de dolo eventual, conseguindo assim, em que pese a realização do tipo objetivo, esquivar-se do tratamento próprio atribuído aos autores de crimes dolosos, beneficiando-se das penas mais moderadas, de delitos culposos, ou ainda, da impunidade, nos casos em que a modalidade culposa inexiste. Para Ragués, portanto, nas hipóteses em que o sujeito decide permanecer cego, deixar a conduta impune é insatisfatório e resulta estranho afirmar que, quem evitou conhecer agiu de maneira negligente. Dentre os exemplos mencionados pelo autor, encontra-se o do diretor de uma empresa que emite uma ordem aos seus colaboradores para que não recebam nenhuma notificação oficial; ou ainda, o diretor que divulga a criação de um e-mail para receber comunicações referentes às irregularidades no funcionamento da empresa, e-mail este que, desde o início estava disposto a não abrir nunca ${ }^{42}$.

Tomemos como exemplo o leading case, United States vs Jewell, em que parece difícil afirmar o dolo, pois quem recebe dinheiro para cruzar a fronteira (México X Estados Unidos) com seu automóvel, consciente de que o veículo tem um compartimento secreto e de que nele há alguma carga, pode até saber que anda mal, entretanto, não se pode afirmar que se trata de 110 libras de maconha, como era o caso, ou de armas, ou de pornografia infantil, ou de órgãos, enfim, o agente não tem como saber. E em tais casos, há que se reconhecer a impossibilidade de fundamentar o dolo ${ }^{43}$, integrado pela consciência (plena, e não potencial) e pela vontade.

\section{A IMPUTAÇÃO SUBJETIVA: UMA ANÁLISE CRÍTICA DA IGNORÂNCIA DELIBERADA A LUZ DO ORDENAMENTO JURÍDICO BRASILEIRO}

A cada modelo de Estado implica uma particular concepção de Direito Penal e de sua função. A imagem do Estado (social) e democrático de Direito brasileiro deve oferecer o ponto de partida para determinar a função do Direito Penal, que por sua vez, deve servir de base não só à teoria da pena, mas também à teoria do delito. Assim, se cada modelo de Estado determina uma concepção de Direito Penal, tal concepção deve fornecer o suporte de seus dois componentes básicos, quais sejam, a pena e o delito: "Estado, Direito Penal, pena e delito encontram-se numa relação de estreita dependência”. Com efeito, a teoria do delito determina as fronteiras mínimas do que pode ser proibido e punido, respondendo à pergunta de que elementos devem estar presentes,

\footnotetext{
${ }^{41}$ RAGUÉS I VALLÈS, Ramon. Op. cit., p. 18-19. Tradução livre.

${ }^{42}$ Idem. Ibidem. Em tais exemplos é possível notar que a realização da conduta típica se dá sem que o agente, no momento da execução, tenha o conhecimento exigido pelo elemento subjetivo do tipo, e tal estado de desconhecimento decorre de uma decisão prévia do indivíduo de não querer obter os conhecimentos. Não há que falar-se em actio libera in causa, onde o que se provoca é a própria inimputabilidade para se cometer, posteriormente, neste estado, um delito. Por sua vez, na ignorância deliberada estrita, o que se produz intencionalmente é o desconhecimento dos fatos, ou seja, um erro sobre a base fática da imputação, configurando erro de tipo (JOSHI JUBERT, Ujala. La doctrina de la actio libera in causa en Derecho Penal. Barcelona: Bosch, 1992, p. 84).

${ }^{43}$ GRECO, Luís. Op. cit., p. 69-70.
} 
minimamente e com caráter geral, para que algo seja jurídico-penalmente proibível e punível. E isso dependerá, portanto, da função que se atribui ao Direito Penal e dos limites impostos de modo geral ao seu exercício ${ }^{44}$.

Nesse diapasão, a Constituição Federal estampou em seu art. 1. ${ }^{\circ}$, III, a dignidade humana como fundamento da República Federativa do Brasil, posicionando-a como núcleo axiológico de todo o ordenamento jurídico pátrio, de modo que, é a pessoa merecedora de tratamento prioritário no Estado, para quem e por quem se construiu e idealizou a figura do Estado moderno, como entidade responsável por assegurar a proteção jurídica dos direitos fundamentais, proteção esta que deverá se dar sempre nos termos das diretrizes constitucionais ${ }^{45}$. E justamente por isso,

"...o direito valora positivamente certos bens, que, ao gozarem de sua proteção, se convertem em bens jurídicos. De modo consequente, o direito valora negativamente as ações que lesionam ou põem em perigo os bens jurídicos. Pois bem, dada a limitação do saber causal dos seres humanos, o direito não pode proibir a simples causação de resultados, mas tão somente a realização de ações dirigidas pela vontade à produção de lesão ou de perigo de lesão de um bem jurídico. Só assim, mediante a referência ao conteúdo da vontade, portanto, ao dolo, poder-se-á precisar a conduta proibida ou ordenada"46.

Sob essa perspectiva, concebe-se a teoria do delito como um sistema condicionado e estruturado sobre dados ontológicos, sobre estruturas lógico-objetivas, sendo que o Direito passa a atuar como instrumento destinado a influenciar a vontade e orientar o comportamento do homem, como uma força conformadora da vida em sociedade. Assim, atribui-se ao Direito Penal a função de exclusiva proteção dos bens jurídicos, proibindo-se os indivíduos de causar lesão ou perigo a tais bens, bem como, determinando-se que busquem evitar comportamentos nesse sentido ${ }^{47}$.

E a partir dessa premissa, a conduta humana objeto da norma penal, é tida como "o exercício de uma atividade final" ${ }^{48}$. A ação passa a ser concebida como um acontecimento final e não puramente causal. E esse "caráter final da ação baseia-se no fato de que o homem, graças ao seu saber causal, pode prever, dentro de certos limites, as possíveis consequências de sua conduta, designar-lhes fins diversos e dirigir sua atividade" 49 . E considerando que a ação finalista se baseia na vontade humana configuradora do acontecer causal, concebe-se que o liame subjetivo que une o agente ao efeito da ação, integra o injusto. É nesse contexto que o dolo e a culpa deixam a culpabilidade - superando a concepção causalista - e passam a integrar o tipo ${ }^{50}$.

\footnotetext{
${ }^{44}$ MIR PUIG. Santiago. Op. cit., p. 113-114.

${ }^{45}$ Nesse sentido vide: PRADO, Luiz Regis. Bem jurídico-penal e Constituição. 6. ed. São Paulo: Revista dos Tribunais, 2013 , p. 75.

${ }^{46}$ CEREZO MIR, José. Ontologismo e normativismo na teoria finalista. Ciências Penais. v. 1, 2004, p. 03. Disponível em: <http://www.professorregisprado.com/artigos.html>. Acesso em 04 set. 2016.

${ }^{47}$ LOURENZO COPELLO. Patricia. Dolo y conocimiento. Valencia: Tirant lo Blanc, 1999, p. 27.

${ }^{48}$ WELZEL, Hans. Op. cit., p. 25.

${ }^{49}$ Idem. Ibidem.

${ }^{50}$ É a partir de Welzel, com sua teoria finalista da ação, que surge tal compreensão, entendendo-se que "uma ação converte-se em delito se infringe a ordem da comunidade de um modo previsto em um dos tipos legais e pode ser reprovável ao autor no conceito de culpabilidade. A ação tem que infringir, por conseguinte, de um modo determinado a ordem da comunidade: tem que ser 'típica'
} 
No Brasil, a Constituição Federal de 1988, e o Código Penal, especialmente a partir da reforma de 1984, constroem a responsabilidade penal do indivíduo a partir teoria finalista da ação, conforme se demonstrou, a partir da preocupação do legislador constituinte em estabelecer, como fundamento da República, a dignidade da pessoa humana (art. 1. ${ }^{\circ}$, III, CF), bem como, dentre os direitos e garantias individuais a preocupação com a individualização e a pessoalidade das penas (art. 5. ${ }^{\circ}, \mathrm{XLV}$ e XLVI, CF) ${ }^{51}$, bem como, "no princípio da igualdade (art. 5. ${ }^{\circ}$ caput, CF), que veda o mesmo tratamento ao culpável e ao inculpável”52. Assim também, o legislador ordinário estabeleceu que somente haverá responsabilização penal a título de dolo ou de culpa, ou seja, subjetiva (arts. 18 e 19, CP).

O Direito Penal, ao superar sua origem objetiva, procurou tratar a pena como dependente de "uma vontade condenável do agente" 53 . Estabelece-se por isso, maior medida de justiça ao castigo, que passa a apreciar além do fato objetivamente danoso, o elemento subjetivo, o ato interno da vontade reprovável ${ }^{54}$.

E não há como falar do princípio da imputação subjetiva sem mencionar o da culpabilidade, já que aquele surge a partir da definição deste. Concebe-se, inicialmente, a imputação subjetiva como sendo a culpabilidade em sentido estrito em razão da "tardia vigência da teoria jurídica do delito neoclássica (pensamento neokantiano), que incluía no conceito de culpabilidade, o dolo e a culpa, como suas formas" 55 .

Para o princípio da imputação subjetiva, somente se responsabilizará alguém que tenha agido (ou se omitido) dolosa ou culposamente. Mais ainda, a sanção jurídico-penal imposta "deve ser proporcional ou

e 'antijurídica'; e há de ser, além disso, reprovável ao autor como pessoa responsável: tem que ser culpável. A tipicidade, a antijuridicidade e a culpabilidade são os três elementos que convertem a ação em delito. A culpabilidade - a responsabilidade pessoal pelo fato antijurídico - pressupõe a antijuridicidade do fato, do mesmo modo que a antijuridicidade tem que estar, por sua vez, concretizada nos tipos legais. A tipicidade, a antijuridicidade e a culpabilidade estão vinculadas logicamente de tal modo que cada elemento posterior do delito pressupõe o anterior" (WELZEL, Hans. Op. cit., p. 58). E ao Direito Penal interessa, como se sabe, o estudo do delito. E sob uma perspectiva analítica tripartida, o crime é definido como sendo uma conduta típica, antijurídica e culpável (Nesse sentido vide: WELZEL, Hans. Op. cit., p. 80; CEREZO MIR, José. Op. cit., p. 50; PRADO, Luiz Regis. Op. cit., p. 66; ZAFFARONI, Eugenio Raúl. Manual de Derecho penal: parte general. Buenos Aires: Ediar, 1977, p. 257 SANTOS, Juarez Cirino dos. A moderna teoria do fato punível. 4. ed. Curitiba: Lúmen Juris, 2005, p. 1; DESTEFENNI, Marcos. O injusto penal. Porto Alegre: Sergio Fabris, 2004, p. 13. Há entretanto que defenda uma concepção bipartida de delito, para quem a censurabilidade da conduta é externa ao injusto penal, servindo como condição para a imposição de uma sanção penal (JESUS, Damásio E. Direito Penal. 8. ed. São Paulo: Saraiva, 1983, v.1, p. 410).

${ }^{51}$ Nesse sentido, Luis Luizi aponta como dispositivos esparsos que consagram o princípio da culpabilidade, da responsabilidade pessoal ou da responsabilidade subjetiva, da responsabilidade pelo fato, da presunção de inocência e da individualização da pena, na Constituição (LUIZI, Luis. Os princípios constitucionais penais. 2. ed. Posto Alegre: Sergio Fabris, 2003, p. 32). Culpabilidade esta que deve ser compreendida também como uma garantia contra os excessos da responsabilidade objetiva e também como uma exigência que se soma à relação de causalidade para reconhecer a possibilidade de impor pena. Fala-se aqui em princípio da culpabilidade em sentido estrito, de modo que, as lesões ou colocações em perigo de bens jurídicos-penais não são suficientes para que pese uma carga penal sobre o autor. Logo, "não há pena sem dolo ou culpa". Nesse passo, a verificação objetiva dessas lesões corresponde, posteriormente, uma verificação subjetiva, que diz respeito ao dolo ou a culpa (CERNICHIARO, Luiz Vicente; COSTA JUNIOR, Paulo José. Direito Penal na Constituição. 3. ed. São Paulo. Revista dos Tribunais, 1995, p. 126).

${ }^{52}$ PRADO, Luiz Regis. Tratado de Direito Penal brasileiro: parte geral: volume 1. São Paulo: Revista dos Tribunais, 2014, p. 178.

${ }^{53}$ BRUNO, Aníbal. Direito Penal. 4. ed. Rio de Janeiro: Forense, 1984, v. 2, p. 24.

${ }^{54}$ DESTEFENNI, Marcos. Op. cit., p. 49. 
adequada à gravidade do desvalor da ação representado pelo dolo ou culpa, que integra o tipo de injusto, e não a culpabilidade". Restam afastadas, portanto, a possibilidade de responsabilidade penal objetiva ou pelo resultado fortuito decorrente de atividade lícita ou ilícita ${ }^{56}$.

E o dolo, como elemento geral da ação finalista é definido como produto da consciência e da vontade de realização dos elementos objetivos do tipo. Existem portanto, dois elementos no dolo: o primeiro, de ordem intelectiva, é a consciência; e o segundo, de ordem volitiva, é a vontade ${ }^{57}$. Nesse sentido, é precisa a lição de Luiz Regis Prado:

"Compreende o dolo, como face subjetiva do tipo, os elementos cognitivo ou intelectual consciência atual da realização dos elementos objetivos do tipo (conhecimento da ação típica, representação fática) -, e volitivo, intencional ou emocional - vontade de realização dos elementos objetivos do tipo (vontade intencional, vontade reitora da conduta, finalidade típica). Isso significa o agasalho de uma concepção dualista: dolo exige conhecimento (saber) e vontade (querer) ${ }^{n 5}$

Por aí que o art. 18, I, do Código Penal traz em seu bojo duas modalidades de dolo, o direto e o eventual. Fala-se em dolo direto nos casos em que o agente quis o resultado; e em dolo eventual, quando o agente assume o risco de produzi-lo ${ }^{59}$.

Além do dolo, o Código Penal também possibilitou que a conduta fosse atribuída ao agente a título de culpa, nos casos em que o agente deu causa ao resultado por imprudência, negligência ou imperícia. Note-se que, enquanto no fato doloso, o agente, desde logo, vincula a realização do tipo em torno de seu objeto de referência (querido e conhecido), no fato culposo, ao contrário, não o faz, sendo que a realização típica ocorre contrariamente ao esperado ${ }^{60}$.

Há na figura culposa uma violação ao dever objetivo de cuidado, desvalorada tão somente por ser descuidada, punindo-se "um comportamento mal dirigido a um fim irrelevante (ou ilícito)" ${ }^{61}$. E esta pode ser sem previsibilidade, inconsciente, também chamada de culpa comum. Ou ainda, com previsibilidade, dita culpa consciente, em que o agente prevê o resultado, mas não o aceita, pensando pode-lo evitar ${ }^{62}$.

São essas então, as quatro hipóteses em que se pode subsumir a conduta em uma figura típica no ordenamento jurídico-penal pátrio, quais sejam: o dolo direto, o dolo eventual e a culpa inconsciente e a culpa consciente. E não há, portanto, que se falar em ignorância deliberada como uma nova espécie de imputação, por

\footnotetext{
${ }^{55}$ PRADO, Luiz Regis. Op. cit., p. 178.

${ }^{56}$ Idem. Ibidem.

${ }^{57}$ Nesse sentido: WELZEL, Hans. Op. cit., p. 83; CEREZO MIR, José. Op. cit., p. 50; PRADO, Luiz Regis. Op. cit., p. 387; BRUNO, Aníbal. Op. cit., p. 26; ZAFFARONI, Eugênio Raúl. Op. cit., p. 257; SANTOS, Juarez Cirino dos. Op. cit., p. 64; DESTEFENNI, Marcos. Op. cit., p. 35; BRANDÃO, Cláudio. Op. cit., p. 173;

${ }^{58}$ PRADO, Luiz Regis. Op. cit., p. 388.

${ }^{59}$ Art. 18 - "Diz-se o crime: I - doloso, quando o agente quis o resultado ou assumiu o risco de produzi-lo".

${ }^{60}$ TAVARES, Juarez. Op. cit., p. 271.

${ }^{61}$ PRADO, Luiz Regis. Op. cit., p. 400.
} 
duas razões fundamentais:

1..$^{\circ}$ Adotar a doutrina da ignorância deliberada contraria os princípios basilares do Direito Penal, princípios incorporados a partir dos valores liberais, sendo que as normas concernentes ao Direito Penal se traduzem, também, em postulados que atuam em defesa das garantias individuais, restringindo a intervenção penal do Estado (v.g. princípio da imputação subjetiva) ${ }^{63}$.

2. $)$ O legislador ordinário não contemplou, dentre as hipóteses de responsabilização penal previstas no art. 18, I e II, do Código Penal, a ignorância deliberada, mas tão somente o dolo e a culpa. Logo, ou os elementos objetivos do tipo são praticados juntamente com esses, e o tipo estará realizado na modalidade dolosa ou culposa, se prevista, ou então, não haverá como imputar objetivamente a conduta àquele que ignora tais elementos. Há quem defenda que o problema da cegueira deliberada pode ser também um problema do dolo eventual, posto que "todo dolo eventual se enquadraria no que se entende por cegueira deliberada" ${ }^{4}$.

Tal doutrina gera, em verdade, mais problemas do que soluções, podendo converter-se em soluções injustas, na medida em que permite que a pena deixe de refletir adequadamente o desvalor jurídico que merece a conduta do sujeito ${ }^{65}$, cumprindo somente fins de política-criminal, baseados na necessidade de se superar os aparentes déficits de punibilidade, especialmente no que diz respeito aos crimes de tráfico de drogas e de lavagem de dinheiro. Ademais disso, reduz-se consideravelmente as exigências de prova em alguns delitos, eximindo o julgador de indicar os indícios incidentes na verificação das regras de experiência que autorizam a condenação. Trata-se, portanto, de referencial demasiadamente elástico para fundamentar a aplicação do dolo eventual à realidade brasileira ${ }^{66}$.

Ressalte-se, outrossim, que o dolo eventual, exige para sua configuração, o elemento cognitivo, sendo impossível assumir o risco de produzir o resultado daquilo que não se conhece, ainda que minimamente ${ }^{67}$. E também, porque o erro sobre elemento constitutivo do tipo exclui o dolo (art. 20, CP).

Há, ao se tratar da ignorância deliberada, uma inversão na ordem daquilo que deve ser, efetivamente, analisado. Pois prioriza-se o que o indivíduo não sabe - os ditos conhecimentos que deveria e podia conhecer -, ao

\footnotetext{
${ }^{62}$ TAVARES, Juarez. Op. cit., p. 380; PRADO, Luiz Regis. Op. cit., p. 406

${ }^{63}$ LUIZI, Luis. Op. cit., p. 12.

${ }^{64}$ LAUFER, Christian; GALVÃO DA SILVA, Robson A. Op. cit., p. 3.

${ }^{65}$ FEIJOO SÁNCHEZ, Bernardo. Op. cit., p. 10.

${ }^{66}$ SILVEIRA, Renato de Mello Jorge. Op. cit., p. 2-3.

${ }^{67}$ Não há que se admitir, nesse passo, a sugestão de tornar objetivo e elemento subjetivo da conduta sob o argumento de que é impossível a indicação dos meios que possibilitem a identificação do dolo como realidade psicológica, em razão da intenção subjetiva ser inacessível fisicamente e pela necessidade de se ter uma verdade real no processo (BUSATO, Paulo César; DÍAZ PITA, María del Mar; MARTÍNEZ-BUJÁN PEREZ, Carlos. Modernas tendências sobre o dolo em direito penal. Rio de Janeiro: Lumen Juris, 2008, p. 100). Também não se pode aceitar o dolo sem a representação intelectual, como indicia Roxin ao dispor que, age com dolo eventual aquele que, suspeitando da presença dos elementos do tipo, mas sem a certeza, atua de modo a
} 
invés de aferir-se aquilo que está devidamente representado pelo autor ao decidir prosseguir em sua realização. Certo é, que sempre será possível ao agente conhecer melhor as circunstâncias do caso concreto, entretanto, não é correto enaltecer aquilo que o sujeito poderia vir a conhecer ${ }^{68}$. Nesse sentido, importa distinguir que, o conhecimento potencial dos elementos do tipo objetivo, não dão ensejo ao dolo eventual, diferentemente do que ocorre com o conhecimento potencial da ilicitude do fato, que pode sim caracterizar a culpabilidade ${ }^{69}$. Logo, o mínimo de representação das circunstâncias do tipo objetivo deverá estar efetivamente presente no momento da conduta, não se aceitando que o agente pudesse vir a ter um conhecimento mínimo exigido caso se esforçasse para tanto, pois "o conhecimento exigível para a configuração de qualquer espécie dolosa deve ser sempre atual, e não potencial"70. Mais ainda, "apenas o conhecimento da totalidade das circunstâncias da ação proporciona o conhecimento da ilicitude e permite aferir a presença do dolo"71.

\section{CONCLUSÃO}

O fenômeno criminal, por complexo e multifacetário que é, merece constante atenção das ciências que estudam analisam as sociedades humanas. Seja sob uma perspectiva meramente jurídica, consubstanciada em mera violação da lei penal, seja por uma visão sociológica do fenômeno ou mesmo sob uma angulação biopsicológica, de fato o tema é merecedor de observação.

O "problema da criminalidade" tem gerado uma forte demanda de políticas criminais duras com o recrudescimento das leis e ampliação de tipos penais, muitas vezes desprovidos de seu exclusivo objeto de proteção, qual seja o bem jurídico-penal. Ademais disso, a necessidade de proteção dos bens jurídicos transindividuais, faz emergir, dia a dia, a preocupação de proteção da sociedade, induzindo-nos a admitir quaisquer meios para alcançar tal fim, esquecendo-se da pessoa, que é o centro e o fim do Estado.

O crime como fenômeno social e, portanto, humano, deve ser estudado à luz da natureza desse ser complexo cuja dignidade transcende superficiais conceitos legais estabelecidos em épocas de lógica pouco democrática. Veja-se que o delito não só é um "fenômeno social normal", como também cumpre outra função importante, qual seja, a de manter aberto o canal de transformações de que a sociedade precisa.

Afirmar-se que o ser humano tem livre-arbítrio sobre seus atos, podendo posicionar-se ou não, de acordo com a lei - sem uma coerente e necessária observação de fatores criminogenéticos, vindos da própria constituição

\footnotetext{
possivelmente produzir o resultado típico (ROXIN, Claus. Teoría del Delito en la Discusión Actual. Lima: Grijley, 2007, p. 201. Tradução livre. ${ }^{68}$ LAUFER, Christian; GALVÃO DA SILVA, Robson A. Op. cit., p. 3.

${ }^{69}$ WELZEL. Hans. Op. cit., p. 44 e ss.

${ }^{70}$ LAUFER, Christian; GALVÃO DA SILVA, Robson A. Op. cit., p. 2-3
} 
do delinquente ou do meio social em que vive -, pode nos conduzir a um infecundo e arbitrário Direito Penal das presunções, o que seria odioso do ponto de vista democrático.

Nesse diapasão, não se pode tergiversar sobre os direitos fundamentais conquistados, a duras penas, pela humanidade, a pretexto de "proteção social", ou ainda, de se buscar qualquer fim alheio à proteção do indivíduo. $\mathrm{O}$ intuito de punir não pode permear a criação e aplicação do Direito Penal. Em primeiro lugar, deve se assegurar os direitos e garantias fundamentais, e não a efetividade e aplicação da lei penal.

E dentre os direitos fundamentais, está o direito individual a imputação subjetiva, direito penalconstitucional que limita e orienta a intervenção penal como princípio político-criminal garantidor ${ }^{72}$, e que surge a partir da definição material de culpabilidade, de seu aspecto empírico-normativo e normativo-constitucional, abonando em favor da autodeterminação humana, onde o homem é tido como ser digno, livre e responsável ( $v \cdot g$. teoria constitucional da culpabilidade).

Assim, o Direito, feito pelo homem e para o homem, deve estar em sintonia com a natureza das coisas, qual seja, a natureza humana. Não há outra compreensão possível! O oposto, ou seja, a promoção da "proteção social" em detrimento do indivíduo, seria um retorno a Escola de Kiel.

E nesse passo, ganha força e autonomia o princípio da imputação subjetiva, superando a influência do Direito Penal germânico, que apregoava a punição a partir do resultado. Essa evolução promovida inicialmente pela teoria neoclássica do delito, avança ainda mais com o finalismo welzeliano, quando se opera um deslinde entre o princípio da culpabilidade e o da imputação subjetiva, retirando-se o dolo e a culpa da culpabilidade e alocando-os na conduta, o que inviabiliza uma análise integrada de culpabilidade e imputação subjetiva.

Segundo o princípio da imputação subjetiva, não há delito ou pena sem dolo ou culpa, de modo que, só pertence a determinada pessoa o evento ou ato por ela realizado materialmente, cuja exteriorização possa ser controlada pela vontade de realização, que é a vontade típica e ilícita, que tem no dolo ou na culpa, o seu conteúdo. O oposto seria um retorno ao princípio qui versatur in re illicita respondit etiam pro $\mathrm{Casu}^{73}$, onde aquele que pratica um ato ilícito responde por todas as consequências deste ato, ainda que por ele não foram queridas, nem

\footnotetext{
${ }^{71}$ GRACIA MARTÍN, Luis. Pyeto docente y de investigación em Derecho penal. p. 324, apud PRADO, Luiz Regis. Tratado de Direito Penal brasileiro: parte geral: volume 2. São Paulo: Revista dos Tribunais, 2014, p. 496.

${ }^{72}$ Conforme já se demonstrou, a partir da preocupação do legislador constituinte em estabelecer, como fundamento da República, a dignidade da pessoa humana (art. 1. ${ }^{\circ}$, III, CF), bem como, dentre os direitos e garantias individuais a preocupação com a individualização e a pessoalidade das penas (art. 5. , XLV e XLVI, CF), bem como, "no princípio da igualdade (art. 5..$^{\circ}$ caput, CF), que veda o mesmo tratamento ao culpável e ao inculpável” (PRADO, Luiz Regis. Tratado de Direito Penal brasileiro: parte geral: volume 1. São Paulo: Revista dos Tribunais, 2014, p. 178). Assim também, o legislador ordinário, estabeleceu que somente haverá responsabilização penal a título de dolo ou de culpa, ou seja, subjetiva (arts. 18 e 19, CP).

${ }^{73}$ Este princípio teve sua origem no Direito Penal da Idade Média, inspirado fundamentalmente no critério da responsabilidade penal objetiva. Aparece primeiramente nas fontes do Direito Canônico e representou um dulcificação da responsabilidade objetiva do Direito Penal germânico (CEREZO MIR, José. Temas fundamentales del Derecho Penal. Santa Fe: Rubinzal-Culzoni, 2002, v. I, p. 65).
} 
previstas, nem previsíveis.

Por todos os motivos até aqui expostos, propugna-se pelo total rechaço a adesão da teoria da ignorância deliberada no ordenamento jurídico pátrio, que promove: ora a desnecessidade da persecução penal estatal provar os elementos volitivo e cognitivo em que se baseia a figura dolosa; ora a inversão da carga probatória sobre este fim.

Convém frisar, outrossim, que a própria expressão "ignorância deliberada” não é idiomática e nem conceitualmente adequada, de modo que, se há a intenção de ignorar, é porque, na realidade, se sabe o que se ignora. Ninguém pode ter a intenção daquilo que não sabe! A contradição in terminisé evidente.

\title{
A CRITICAL ANALYSIS THE THEORY OF WILLFUL BLINDNESS BASED ON THE PRINCIPLE OF SUBJECTIVE IMPUTATION
}

\begin{abstract}
The present work aims at the critical analysis and the exploration of a great legal-penal problem of the actuality, what is the import the theory of willful blindness to enable the imputation of conduits that do not meet the imputation parameters established in our legal system, violating the principle of subjective imputation. For that, we studied the historical origin the theory of willful blindness, presenting judgments of English Law, US Law, Spanish Law and Brazilian Law. It was also demonstrated, the use of the theory in the Anglo-Saxon legal system and, later, its importation into the Continental System. Then, we discussed the proposed definition and doctrinal delimitation of the present theory, followed by a critical analysis because of its incompatibility with the politicalcriminal principle of subjective imputation.
\end{abstract}

Keywords: Deliberate Ignorance; Willful Blindness; Culpability; Subjective Imputation.

\section{REFERÊNCIAS BIBLIOGRÁFICAS}

BECK, Francis. A Doutrina da Cegueira Deliberada e sua (In) Aplicabilidade ao Crime de Lavagem de Dinheiro. Revista de Estudos Criminais. Sapucaia do Sul, n. 41, p. 45-68, set. 2011.

BITENCOURT, Cezar Roberto. Teoria geral do delito: uma visão panorâmica da dogmática penal brasileira. Coimbra: Almedina, 2007.

BRANDÃO. Cláudio. Curso de Direito Penal: parte geral. 2. ed. Rio de Janeiro: Forense, 2010.

BRUNO, Aníbal. Direito Penal. 4. ed. Rio de Janeiro: Forense, 1984, v. 2.

BUSATO, Paulo César; DÍAZ PITA, María del Mar; MARTíNEZ-BUJÁN PEREZ, Carlos. Modernas tendências sobre o dolo em direito penal. Rio de Janeiro: Lúmen Juris, 2008. 
CEREZO MIR, José. Ontologismo e normativismo na teoria finalista. Ciências Penais. v. 1, 2004. Disponível em: $<$ http://www.professorregisprado.com/artigos.html>. Acesso em 04 set. 2016.

Temas fundamentales del Derecho Penal. Santa Fe: Rubinzal-Culzoni, 2002, v. I.

CERNICHIARO, Luiz Vicente; COSTA JUNIOR, Paulo José. Direito Penal na Constituição. 3. ed. São Paulo. Revista dos Tribunais, 1995.

DESTEFENNI, Marcos. O injusto penal. Porto Alegre: Sergio Fabris, 2004.

FEIJOO SÁNCHEZ, Bernardo. La teoría de la ignorancia deliberada en Derecho penal: una peligrosa doctrina jurisprudencial. InDret: Revista para el análisis del Derecho. v. 3. Barcelona, 2015, p. 3. Disponível em: $<$ http://www.indret.com/pdf/1153.pdf>. Acesso em: 05 set. 2016.

GRACIA MARTÍN, Luis. Proyecto docente y de investigación en Derecho penal.

GRECO. Luís. Comentario al artículo de Ramón Ragués. Discusiones: Ignorancia Deliberada y Derecho Penal. v. 13-2, 2013, 20.15 .2 Disponível em: <http://www.academia.edu/22655140/Discusiones_XIII_Ignorancia_deliberada_y_derecho_penal $>$. Acesso em: 02 set. 2016.

HUSAK, Douglas N.; CALLENDER, Craig A. 'Willful Ignorance, Knowledge, and the 'Equal Culpability' Thesis: a Study of the Deeper Significance of the Principle of Legality", Winconsin Law Review, Madison, 1994. Disponível em: <https:/ /itigation-essentials.lexisnexis.com/>. Acesso em 04 set. 2016.

JESUS, Damásio E. Direito Penal. 8. ed. São Paulo: Saraiva, 1983, v.1.

JOSHI JUBERT, Ujala. La doctrina de la actio libera in causa en Derecho Penal. Barcelona: Bosch, 1992.

KLEIN, Ana Luiza. A doutrina da cegueira deliberada aplicada ao delito de lavagem de capitais no Direito Penal brasileiro. Porto Alegre: Edipucrs, 2012, p. 2-3, Disponível em: <ebooks.pucrs.br/edipucrs/anais/cienciascriminais/III/4.pdf>. Acesso em 02 set. 2016.

LAUFER, Christian; GALVÃO DA SILVA, Robson A. A teoria da cegueira deliberada e o Direito Penal brasileiro. Boletim IBCCrim. v. 204, 2009, p. 2. Disponível em: <http://www.ibccrim.org.br/boletim_artigo/3980-Ateoria-da-cegueira-deliberada-e-o-direito-penal-brasileiro>. Acesso em: 01 set. 2016.

LOURENZO COPELLO. Patricia. Dolo y conocimiento. Valencia: Tirant lo Blanc, 1999.

LUBAN, David. "Contrived Ignorance”. Georgetown Law Review. v. 87. Toronto, 1999, p. 968. Disponível em: $<$ http://scholarship.law.georgetown.edu/cgi/viewcontent.cgi?article=2765\&context=facpub $>$. Acesso em: 03 set. 2016.

LUIZI, Luis. Os princípios constitucionais penais. 2. ed. Posto Alegre: Sergio Fabris, 2003.

MORO, Sérgio Fernando. Sobre o elemento subjetivo no crime de lavagem. In.: Lavagem de dinheiro: comentários a lei pelos juízes das varas especializadas em homenagem ao Ministro Gilson Dipp. BALTAZAR JUNIOR. José; MORO, Sérgio Fernando (org.). Porto Alegre: Livraria do Advogado, 2007. 
MIR PUIG, Santiago. Direito penal: fundamentos e teoria do delito. Trad. Cláudia Viana Garcia e José Carlos Nobre Porciúncula Neto. São Paulo: Revista dos Tribunais, 2007.

PRADO, Luiz Regis. Bem jurídico-penal e Constituição. 6. ed. São Paulo: Revista dos Tribunais, 2013.

Tratado de Direito Penal brasileiro: parte geral: volume 1. São Paulo: Revista dos Tribunais, 2014.

Tratado de Direito Penal brasileiro: parte geral: volume 2. São Paulo: Revista dos Tribunais, 2014.

RAGUÉS I VALLÈS, Ramon. La ignorancia deliberada en derecho penal. Barcelona: Atelier, 2007.

Mejor no saber: sobre la doctrina de la ignorancia deliberada en Derecho penal. Discusiones:

Ignorancia Deliberada y Derecho Penal. v. 13-2, 2013, p. 15. Disponível em: <http://www.academia.edu/22655140/Discusiones_XIII_Ignorancia_deliberada_y_derecho_penal >. Acesso em: 02 set. 2016).

ROBBINS, Ira P. The Ostrich Instruction: Deliberate Ignorance as a Criminal Mens Rea. The Journal of

Criminal Law Criminology. Chicago, 1990, p. 195. Disponível em: scholarlycommons.law.northwestern.edu/jclc/vol81/iss2/1/.Acesso em 02 set. 2016.

ROXIN, Claus. Teoría del Delito en la Discusión Actual. Lima: Grijley, 2007.

SANTOS, Juarez Cirino dos. A moderna teoria do fato punível. 4. ed. Curitiba: Lumen Juris, 2005.

SILVEIRA, Renato de Mello Jorge. Cegueira deliberada e lavagem de dinheiro. Boletim IBCCrim. v. 246, 2013, p. 3. Disponível em: <http://www.ibccrim.org.br/boletim_artigo/4864-Cegueira-deliberada-e-lavagem-dedinheiro>. Acesso em: 01 set. 2016.

TAVARES, Juarez. Direito Penal da Negligência: uma contribuição à Teoria do Crime Culposo. 2. ed. Rio de Janeiro: Lúmen Juris, 2003.

WELZEL, Hans. O novo sistema jurídico-penal: uma introdução à doutrina da ação finalista. Trad. Luiz Regis Prado. 3. ed. São Paulo: Revista dos Tribunais, 2011.

ZAFFARONI, Eugênio Raúl. Manual de Derecho penal: parte general. Buenos Aires: Ediar, 1977.

Trabalho enviado em 06 de novembro de 2017.

Aceito em 19 de janeiro de 2018. 